\title{
Learners' perceptions of learners regarded as having a homosexual orientation in an independent secondary school environment
}

\begin{abstract}
Authors:
Hendrik P. Mostert ${ }^{1}$

Chris Myburgh $^{1}$

Marie Poggenpoel ${ }^{2}$

Affiliations:

${ }^{1}$ Department of Educational Psychology, University of

Johannesburg, South Africa

${ }^{2}$ Department of Nursing

Science, University of

Johannesburg, South Africa

Correspondence to:

Chris Myburgh

Email:

chrism@uj.ac.za

Postal address:

PO Box 524, Auckland Park

2006, South Africa

Dates:

Received: 25 July 2011

Accepted: 06 Aug. 2012

Published: 04 Oct. 2012

How to cite this article: Mostert, H.P., Myburgh, C. \& Poggenpoel, M., 2012,

'Learners' perceptions towards learners regarded as having a homosexual orientation in an independent secondary school environment', Curationis 35(1), Art. \#24, 7 pages. http://dx.doi. org/10.4102/curationis. v35i1.24
\end{abstract}

C 2012. The Authors. Licensee: AOSIS OpenJournals. This work is licensed under the Creative Commons Attribution License.
In schools today discrimination based on sexual orientation takes place on a regular basis. This form of discrimination leads to aggression towards learners perceived to be homosexual, as well as towards those with a homosexual orientation. For more than 15 years South Africa has been a democratic country with laws that protect learners who have a homosexual orientation. Nevertheless, aggression and discrimination towards these learners still occur in schools. Aggression often leads to verbal and physical bullying of the victims by perpetrators. The objectives of this research were to explore and describe Grade 11 learners' experiences of aggression towards learners perceived to be homosexual as well as those with a homosexual orientation in an independent secondary school environment. The research design was qualitative, exploratory, descriptive and contextual in nature. The data for this investigation consisted of essays based on a published newspaper photograph, phenomenological group interviews, observations and field notes. Tesch's method of data analysis was used, and an independent coder assisted. Three themes were identified, discussed and supported by a literature control: that learners experience that it is right and acceptable to have a homosexual orientation; that they experience ambivalence towards homosexual orientation of learners; and experienced feelings that it is wrong to have a homosexual orientation. Recommended guidelines are provided to address aggression towards learners perceived to be homosexual and those with a homosexual orientation.

\section{Introduction}

\section{Background}

Aggression in the form of homophobic bullying is a matter of great concern in schools today (Askew, cited in Tattum \& Lane 1994:59). Says Olweus (2001:21), 'The school is without doubt where most of the bullying occurs.' Homophobia is often expressed visibly, audibly and by acts of violent behaviour brought on by fear. This is an important educational issue that needs to be addressed. Homophobia is an 'effective and powerful' form of abuse and is a rising worry for learners (Smithers 2006:1).

Murray (2001:1) states that this behaviour of discrimination, harassment, isolation and violence has a great impact on the health and well-being of homosexually orientated learners. Victims of aggression experience a variety of negative outcomes, a low self-esteem and the possibility of psychosomatic illness associated with stress, particularly depression and isolation (Wicks-Nelson \& Israel 2003:200; Randall 1996:12).

Homophobia is often associated with the development of gender roles. For boys, traditionally appropriate sex roles, such as breadwinner and decision-maker, and for girls, the traditional sex roles of child-bearing, rearing and nurturing of the family, imply certain personality characteristics. These stereotypes are problematic - girls and boys who do not conform to these roles are accused of being of the opposite sex or homosexual (Forrest, Biddle \& Clift 2006:18). According to Richardson (2006:18), ' ... learners are often bullied if they do not conform to gender stereotypes or are assumed to be homosexual.'

Homophobia (Plummer 2001) starts on the school playgrounds, where labels like 'faggot' and 'poofter' are given to boys whose behaviour is perceived as in any way different. According to Olweus (cited in Sanders \& Phye 2004:64), 'bullying is a growing and significant problem in many schools around the world'; and 'Being a bully or a victim is something that can last for a long time, often for several years' (Olweus 2001:27-28). Learners who are exposed to this kind of negative action find themselves helpless against those perpetrators who harass them (Olweus 2001:10). In some cases the experiences of victimisation are so negative that learners are driven to self-harm 
and suicide (Forrest et al. 2006:19). Victims of bullying that is related to their sexual orientation can experience poor school achievement, which can lead to lateness or absence and, in extreme cases, suicide (Pupils Support Circular 10/99, in Mullen 2001:4; National Union of Teachers 2004a:2).

Learners' aggression towards each other makes the school an unsafe place. Forrest et al. (2006:20) state that young homosexually orientated people suffer homophobic bullying in the form of violent attacks, damaging of personal property, threats, unpleasant looks and stares from peers, as well as being isolated. This kind of bullying takes place in classrooms, corridors and on playgrounds. These forms of aggression can result in serious injury or even death. According to Fraser (2004:141), this type of aggressive behaviour can cause psychological and physical health problems if conflict and oppression are internalised. It is the responsibility of teachers and schools to address homophobic bullying. Fraser (2004:141) states that there are some cases where school personnel ignore, discount or even participate in the harassment of learners. "Harassment occurs in an environment in which negative and harmful stereotypes about homosexual people are left unrecognised or unchecked by those in positions of authority" (Fraser 2004:141). Richardson (2006:18) states that teachers need to 'recognise that learners are often bullied because they do not conform to gender stereotypes or are assumed to be homosexual.'

\section{Problem statement}

In view of the above explication, aggressive behaviour towards learners perceived to be homosexual and those with a homosexual orientation poses challenges to teachers and learners. It was observed that in an independent secondary school environment the challenges resulting from the phenomenon of aggressive behaviour towards learners perceived to be homosexual and those with a homosexual orientation cannot be ignored, as the mental health of perpetrators and victims of such transgressions are at risk. However, little or no research based on empirical investigations exist in the South African literature. In the research described in this article the emphasis was on emotional and physical aggression towards learners perceived to be homosexual and those with a homosexual orientation in an independent secondary school environment.

The specific research question that directed this research was: What are Grade 11 learners' experiences of aggression towards learners perceived to be homosexual and learners with a homosexual orientation?

\section{Objective of the research}

The research adhered to the following objective: to explore and describe Grade 11 learners' experience of aggression towards learners perceived to be homosexual and learners with a homosexual orientation in an independent secondary school environment.

\section{Definition of key concepts}

Aggression: Any type of behaviour towards others with the intention of hurting them, either physically or verbally (Weiten 2007:521).

Independent secondary school environment: In this research, independent school environment refers to a private school (Mostert 2008:8).

Learners: The learners in this study are secondary school learners in Grade 11 (Mostert 2008:8).

Perceived homosexuality: For the purposes of this research this refers to learners who are perceived as being homosexual if they do not conform to specific gender stereotypes, for example assuming that a 'feminine' boy is gay and that a 'masculine' girl is lesbian (Mostert 2008:8; Richardson 2006:18).

\section{Research significance}

The significance of this research is that it will give learners and teachers an understanding of learners' experiences of aggression towards learners perceived as having a homosexual orientation in an independent secondary school environment. This understanding can open discussion about diversity and respect for individuals making their own choices and taking responsibility for these choices. Policy can also be formulated at schools regarding how learners and teachers can monitor safety and how aggressive behaviour needs to be managed.

\section{Research method and design Design}

A qualitative approach is usually chosen when researchers aim to understand a 'lived experience for several individuals about a concept or the phenomenon' (Creswell 2007:57). In the case of this research a qualitative, explorative, descriptive and contextual research design was applied (Mason 2002:25). According to Rudestam and Newton (2001:39) the essence of human experiences concerning the phenomenon as described by the participants is identified.

\section{Research method}

The research method was phenomenological (Creswell 2007:57), hermeneutic, interpretative and open inductive in nature. A phenomenological approach (Creswell 2007:57) aims to understand and interpret the meaning that participants give to experiences in their everyday lives. The researchers place themselves in the participants' 'life world' or 'life setting' (De Vos et al. 2011:273). In this research learners were requested to write essays based on a published newspaper photograph. This was followed by conducting phenomenological group interviews with the participants, making observations and writing field notes. 


\section{Population and sample}

The population for this research was learners in an independent secondary school who experienced aggression towards peers who were perceived to be homosexual or had a homosexual orientation. The first author was an insider at this secondary school, as he teaches Grade 12 learners. He requested the Grade 11 teachers to help identify participants for this research. Inclusion criteria were that learners should be in Grade 11 and have experienced aggression towards learners perceived as homosexual and those with a homosexual orientation. A purposive sample (Dawson 2006:54) of learners adhering to the criteria was taken (De Vos et al. 2011:202). The population was Grade 11 learners in an independent secondary school from a fairly affluent area of Johannesburg, Gauteng (Mostert 2008:29). They had experienced aggression either as a victim or a perpetrator of aggression towards learners perceived to be homosexual and learners with a homosexual orientation. Learners were invited to participate in the research.

Learners in Grade 11 were selected because they are usually between the ages of 16 and 18 years, and this age group was selected because, according to Kohlberg (Hook, Watts \& Cokcroft, 2002: 294-303, most of these learners function at the post-conventional level of moral reasoning. During this age period social contact orientation and a universal ethic principle orientation are prominent. In this regard, the learners in the sample most probably adhered to sustaining general individual rights having been agreed upon by the whole society. Grade 12 learners were not included in the sample because the first author, who did the fieldwork, teaches this group of learners. For the purposes of this article learners who are seen as 'different' and are therefore labelled (accurately or not) as being homosexual were included in the research population.

\section{Data collection methods}

Learners were invited to write essays on a published newspaper photograph (Van Wyk 2006:40) which depicts two men kissing each other after their marriage.

According to Neuman (1997:240), an open-ended question allows a free response. The researchers posed the following question to the participants: Tell me, how is it for you when you look at this photograph? Write an essay on your experience of this photograph. The essays investigated and explored the participants' experiences towards learners perceived to be homosexual and learners with a homosexual orientation, and the participants' experience of aggression towards these learners. The essays of the participants were analysed.

In addition, phenomenological group interviews were conducted with secondary school Grade 11 learners to investigate and explore their experiences towards learners perceived to be homosexual and those with a homosexual orientation, and the participants' experiences of aggression towards these learners. The researchers used different methods to collect data from participants, such as essays (naïve sketches), phenomenological focus groups, observations and field notes (Mostert 2008:29-32; Myburgh \& Strauss 2010:29). Phenomenological group interviews use a group to contribute to a 'controlled experience and then respond to questions about that experience' (Keats 2000:16). Moore (2001:124) states that phenomenological group interviews 'force people to consider how they feel about issues in the light of other people's feelings.' One open-ended question was used in the phenomenological group interviews: Tell me, how is it for you when another learner is homosexual?

Although this was a sensitive topic to address in a phenomenological group interview, it was decided that the learners would be more comfortable to speak openly if they were together in a group to support and encourage each other.

The data collected from the essays on the participants' experiences based on a published newspaper photograph, phenomenological group interviews, observations and field notes were analysed. Data saturation was reached when repetitive patterns of themes and categories were observed in the data collected from participants about their experiences.

\section{Data analysis}

Tesch's method of open coding (Creswell 2007:148) was used to analyse the essays on the photograph, the interviews and observations. The written field notes were also used in the interpretation of the data. Themes and categories were identified. An independent coder and the researchers had a consensus discussion about analysis of the data. The results are structured around themes that were identified, and are supported by direct quotations from the data (Mouton 1996) and substantiated by relevant literature.

\section{Ethical considerations}

According to Babbie (2004:437) the participants in research as human beings should be accorded respect and gratitude for their partnership in the research. The participants were treated with dignity and their autonomy was ensured. Efforts were made to ensure that they could proceed in life with selfrespect. The four principles of an ethical approach that were adhered to throughout implementation of the research project are respect for autonomy, non-maleficence, beneficence and justice (Dhai \& McQuoid-Mason 2011:14-15). The anonymity and protection of the safety of the participants were treated as a priority. Participants participated in the research voluntarily, and the phenomenological focus groups were conducted in English. Ethical clearance was obtained from the University Faculty Ethics Committee and the specific independent school. Parents gave consent for their children to participate, and the learners gave assent before they took part in writing the essays (naïve sketches) or in the focus group interviews. Learners that participated also gave assent for audio-taping of the interviews. 


\section{Trustworthiness}

Guba's model of trustworthiness (De Vos et al. 2011:419421) was applied to ensure the trustworthiness of this research. The four criteria for trustworthiness are truth value through the strategy of credibility, applicability through the strategy of transferability, consistency through the strategy of dependability, and neutrality through the strategy of confirmability. These strategies were applied in this study (Table 1).

\section{Discussion of results}

The findings consisted firstly of the demographics of the sample and secondly analysis of the data collected from the participating learners. The research process was explained to the prospective participants before they were invited to write the essays and before conducting the interviews.

Demographics: Thirty learners (19 males and 11 females) wrote essays (that is, naïve sketches). These participants were between 16 and 17 years of age, and took part in four phenomenological focus group interviews.

Themes from the data analysis: Three themes were evident from the data analysis (Table 2), which are discussed below. After each direct quotation from participants the participant's number, gender, age and from which data set the quotation comes from will be provided.

\section{Theme 1: Learners expressed that it is right and acceptable to have a homosexual orientation}

Theme 1 was related to the learners' internal experiences that it is right and acceptable to have a homosexual orientation. They indicated that it is one's right to choose one's sexual orientation, and that any preference should be treated with respect. The participants stated that learners who have a homosexual orientation are regarded as being brave. In response to their peers who are perceived to have a homosexual orientation, learners manifested a mature perspective towards them.

The following are excerpts from the participants' essays and interviews:

'I have nothing wrong with homosexuality.'(Participant 2, female, 16 years, essay)

'I think if two people are happy then there should be nothing wrong with it.'(Participant 7, male, 17 years, interview)

'I don't feel uncomfortable and if they are happy then you must let them be.'(Participant 30, male, 16 years, essay)

'I don't judge people based on that, so if they're happy, then I'm happy for them.'(Participant 10, female, 17 years, essay)

'It honestly doesn't bother me at all ...' (Participant 1, female, 17 years, interview)

From these quotations it seems as if these participants are of the opinion that learners with a homosexual orientation should be accepted and allowed to make their own choices.
This is in line with Shaffer (2002:511), who opines that moral maturity can be characterised by a person showing feelings of care, concern and integrity. This could indicate an ability to accept someone else in spite of own perceptions and values. Empathetic understanding is indicated by an 'ability to perceive experiences and feelings and their meaning from the standpoint of another person' (Rogers, cited in Pervin \& John 2001:563). An empathetic understanding usually directs a person's approach towards other people and their values, attitudes and behaviour. Westen (1999:658) states that empathy refers to 'feeling for another person who is hurting.'

\section{Theme 2: Learners expressed that they experience ambivalent feelings towards learners perceived to have a homosexual orientation}

The second theme was related to learners' internal experience of ambivalence towards learners perceived to have a homosexual orientation, and those with a homosexual orientation. The learners experienced discomfort and awkwardness towards said learners, including finding it disturbing; but for these learners it does not manifest as aggression. Learners' external manifestation in response to learners perceived to have a homosexual orientation is to feel ambivalence and to react by keeping their distance from said learners.

Quotations from the data illustrating this theme are as follows:

'I don't mind if someone is gay, but it mustn't affect me, you know what I mean?'(Participant 29, female, 16 years, interview)

'If someone's gay, that's fine. It's their business. I don't mind if they are around and talk to me, but that part of them mustn't really come into part of me.'(Participant 7, male, 17 years, essay)

'Okay, I'm straight and whatever. As long as they don't try and make me change who I am ...' (Participant 11, male, 17 years, essay \& interview)

TABLE 1: Strategies to ensure the trustworthiness of the research.

\begin{tabular}{ll}
\hline Strategy & Application \\
\hline Credibility & $\begin{array}{l}\text { The first author has been working at the independent } \\
\text { secondary school for five years } \\
\text { Used naïve sketches, phenomenological group interviews and } \\
\text { observation and field notes for data collection } \\
\text { Peer review throughout the research process } \\
\text { Played audiotapes of interviews back to participants to reach } \\
\text { agreement on their experiences }\end{array}$ \\
Transferability & $\begin{array}{l}\text { Dense description of demographics of participants } \\
\text { Rich description of results with supporting direct quotations } \\
\text { from participants }\end{array}$ \\
Dependability & $\begin{array}{l}\text { Dense description of research methodology } \\
\text { Provided a chain of evidence throughout the research }\end{array}$ \\
\hline TABLE 2: Results of research: Themes.
\end{tabular}


It is necessary to give in-depth consideration to the pattern in the data that learners experience ambivalence towards learners perceived to be homosexual and those with a homosexual orientation. Similar trends are observed where adolescents are trying to establish their own value systems (Kohlberg, cited in Slavin 1991:47-49). This observation can represent a manifestation of adolescents being confronted with challenges in the moral realm that are not clear-cut or do not present in singular modes with simple answers. It is possible that ambivalence concerning an own stance towards own sexuality can influence the acceptance of another person perceived to be 'different'. The realisation of the imperative that other persons are justified and within their rights to have an own opinion, make own decisions and have an own way of life, usually takes place during the adolescent stage of development.

\section{Theme 3: Learners are of the opinion that it is wrong to have a homosexual orientation}

In the third theme it emerged that learners experienced internal feelings that it is wrong to have a homosexual orientation. These learners experienced feelings of disgust, discomfort, fear, irritation and even hatred towards learners perceived to have a homosexual orientation and those with a homosexual orientation. Learners' external manifestation in response to learners perceived to have a homosexual orientation is aggression - either overt or covert.

Quotations from the data illustrating this theme are as follows:

'To me, I'm against homosexuals.'(Participant 14, male, 17 years, essay \& interview)

'Um, it's not right; I feel it's not right that two people of the same sex are together ...' (Participant 22, male, 16 years, essay \& interview)

'To them kissing another guy is normal, I do not agree with that at all.'(Participant 20, male, 17 years, essay \& interview)

'Really, I'm against it.'(P25, male, 17 years, essay \& interview)

'... like I look at him as if like it's not normal.'(Participant 27, male, 16 years, essay \& interview)

'... perceived as not being normal ...'(Participant 16, male, 17 years, essay \& interview)

'I do not associate myself or socialise with any.'(Participant 23, male, 17 years, essay \& interview)

From these quotations it is clear that these Grade 11 participants strongly object to learners perceived to be homosexual and learners with a homosexual orientation. The participating learners stated that they perceived such learners as 'not normal', that they do not agree with such behaviour and do not want to be associated with learners labelled as such. Mullen (2001:9) states that assumptions, myths and negative attitudes towards learners perceived to be homosexual and learners with a homosexual orientation all lead to social exclusion. In this contextual research it seemed that the participants who verbalised that they do not accept other learners perceived to be homosexual, socially excluded the learners. This social exclusion of learners who are perceived as homosexual can be viewed as a form of bullying. In line with this, after conducting research on bullying Oliver and Candappa (2003:5) declared that the most common forms of bullying are name-calling, physical aggression, unwanted sexual touching, social isolation and also sexist, racist and anti-gay abuse. Deliberate exclusion from social groups or intimidation in a group is indicative of social bullying (Lee 2004:10). Sullivan (2001:13) observed that some learners who are perceived to be homosexual and learners with a homosexual orientation become victims of bullying in its various forms.

In Prejudice \& Attitudes to Gay Men - Homophobia (Avert 2005:1) it is stated that if male and female learners do not act in accordance with their gender stereotype, they may be subjected to severe bullying and even given derogatory names (Anderson 1997:65). Westen (1999:790) states that 'stereotypes are often over-generalised, inaccurate, and resistant to new information'. Nevertheless, persons act on their own stereotyping of other persons. Mostert (2008:64) observed that the participants were willing to act on their convictions by indirect external manifestations through, for example, responses. These responses included spreading rumours, insults, name-calling, teasing, bad jokes and mocking. It also manifest physically, for example through bullying, hitting and ganging up against the learners concerned (Mostert 2008:65). Mostert (2008:65) continues by stating that these learners reported that their parents, peers and religion influenced them in forming negative feelings towards the said learners.

\section{Recommendations}

\section{Recommended guidelines to address aggression towards learners perceived to be homosexual and those with a homosexual orientation in an independent secondary school environment}

Based on the findings, guidelines were formulated to address learners' aggression towards learners perceived to be homosexual and those with a homosexual orientation in a secondary school environment. As Tattum states (cited in Tattum \& Lane 1994):

Schools have a responsibility to create a secure and safe environment for children who are in their care so that parents may hand their children over in the confident knowledge that they will be protected from the bullies. (p. 7)

According to Rivers et al. (cited in Sullivan, Cleary \& Sullivan 2004:14), homophobic bullying in schools 'occurs when individuals are singled out and bullied because of their actual or perceived sexual orientation'. This form of aggression causes concern, and is a challenging problem that is complex and difficult to address.

In the effective handling of aggression towards learners perceived to be homosexual and learners with a homosexual orientation, it is essential to follow a whole-school approach. 
According to Sullivan (2001:39) a whole-school approach will be an efficient strategy to handle aggression. A whole-school approach should be aimed at consciously creating a caring, concerned, sympathetic ethos in which all members are respected (Tattum \& Lane 1994:18; National Union of Teachers 2004b:1). According to Farrington (cited in Sanders \& Phye 2004:169), intervention measures against bullying should focus on the whole school. Taking a whole-school approach in addressing this problem needs to include stakeholders such as teachers, school staff, learners, parents and support structures to support and address the fundamental issues of the school. In a whole-school approach everyone involved is consulted and their experiences used to deal with the challenge (Sullivan et al. 2004:55). Sullivan (2001:42) states that an inclusive approach should be followed to include all groups in the development and implementation of a wholeschool anti-aggression approach. Olweus (2001:65) suggests that an intervention programme should aim 'to reduce as much as possible - ideally to eliminate completely - existing aggression'. The goal of a whole-school approach should be 'to eradicate bullying and promote an environment in which it cannot thrive and which strives to improve peer relationships throughout the community' (Randall 1996:47).

In addressing learners with regard to their perceptions towards learners perceived to be homosexual or having a homosexual orientation, cognisance should be taken of the developmental stage of adolescents and the three distinct patterns of judgements observed in these data. Further research must be done with regard to these perceptions and how to address them against the framework of the South African Constitution and Declaration of Human Rights. The suggested guidelines are preliminary, general and broad. Two broad guidelines are suggested, namely:

- A supportive approach should be followed with the objective of following an open, facilitative role when addressing learners' ambivalent feelings towards learners who are perceived to be homosexual and those with a homosexual orientation. The goal should be to assist learners to clarify their own value system.

- A supportive approach should be followed with the objective of addressing learners' perceptions of being opposed to learners perceived to be homosexual and those with a homosexual orientation. In this regard the detrimental effect of negative stereotyping should be explored. Learners can be invited to do self-introspection and assess the detrimental effects of such negative stereotyping of other persons on their own mental health and the mental health of those persons perceived to be of a different orientation. The aim of such an intervention should be re-orientating the aggressive feelings of the former towards other persons perceived to be different from them and their value systems.

\section{Limitations of the study}

The discussion of the results in the literature was based on American and British research on aggression and aggression towards homosexuality, since little such research has been conducted on this topic in Africa (Mostert 2008:97).

\section{Conclusion}

The research's main objective was to explore and describe Grade 11 learners' experience of aggression towards learners perceived to be homosexual and those with a homosexual orientation in a secondary school environment. The first theme identified was related to those learners who expressed the view that it is right or acceptable to have a homosexual orientation. The second theme identified learners experiencing ambivalent feelings towards learners perceived to have a homosexual orientation. The third theme identified indicated that learners are of the opinion that it is wrong or unacceptable to have a homosexual orientation.

Guidelines directed at teachers, school staff, parents and caregivers, learners (victims and perpetrators), as well as the support systems in the school, are recommended in order to prevent and address aggression in the school. Aggression towards learners perceived to be homosexual and learners with a homosexual orientation happens all the time, and has a negative psychological and physical effect on both the perpetrators and the victims. Aggression towards learners perceived to be homosexual and learners with a homosexual orientation has a negative and detrimental effect on both the perpetrators' and victims' mental health. With constructive guidelines, skills and knowledge, such aggression can be prevented or limited in the classroom and in the school with the support of all the stakeholders involved in education.

\section{Acknowledgements}

Dr Jeanette Maritz acted as independent coder and Ms Bernice McNeil conducted the language editing of this paper. The University of Johannesburg is acknowledged for financial support of this project.

\section{Competing interests}

The authors declare that they have no financial or personal relationship(s) which may have inappropriately influenced them in writing this paper.

\section{Authors' contributions}

H.P.M. (University of Johannesburg) conducted the basic research for his master's degree and prepared the initial paper. C.M. (University of Johannesburg) and M.P. (University of Johannesburg) supervised the study and did final preparation of this paper for publication.

\section{References} Anderson, J.D., 1997, 'Supporting the invisible minority', Educational Leadership,
April,64-65.
Avert, 2005, Prejudice \& attitudes to gay men-homophobia, viewed 17 August 2006,
from http://www.avert.org/hsexu3.htm
Babbie, E., 2004, The practice of social research, Wadsworth \& Thompson, Thousand
Oaks.
Coolican, H., 1999, Research methods and statistics in psychology, Hodder \&
Stoughton, London.
Creswell, J.W., 2007, Qualitative inquiry and research design, Sage Publications,
London. 
Dawson, C., 2006, A practical guide to research methods. A user-friendly manual for mastering research techniques and projects, How To Books, Oxford.

De Vos, A.S., Strydom, H., Fouché, C.B. \& Delport, C.S.L. (eds.), 2002, Research at grass roots for the social science and human service professions, Van Schaik Publishers, Pretoria.

Dhai, A. \& McQuiod-Mason, D., 2011, Bioethics, human rights and health law: principles and practice, Juta, Cape Town.

Fraser, M.W., 2004, Risk and resilience in childhood: an ecological perspective, 2nd edn., NASW Press, Washington DC.

Forrest, S., Biddle, G., \& Clift, S., 2006, Talking about homosexuality in the Secondary School, Alvert, West Sussex.

Hook, D., Watts, J. \& Cockcroft, K., 2002, Developmental psychology, UCT Press, Buckingham.

Keats, D.,M., 2000, Interviewing. A practical guide for students and professionals, Open University Press, Oxford

Krefting, L., 1991, 'Rigor in qualitative research. The assessment of trustworthiness', American Journal of Occupation therapy 45(3),214-222.

Lee, C., 2004, Preventing bullying in schools: A guide for teachers and other professionals, Paul Chapman Publishers, London.

Mason, J., 2002, Qualitative researching, Sage, London.

Mouton, J., 1996, Understanding social research, Van Schaik, Pretoria.

Moore, N., 2001, How to do research: The complete guide to designing and managing research projects, 3rd edn., Library Association Publishing, London.

Mostert, H.P., 2008, 'Learners' aggression towards learners perceived as having a homosexual orientation in an independent secondary school environment', M.Ed. dissertation, University of Johannesburg.

Mullen, A., 2001, Inclusive schools: Ending the exclusion of lesbian, gay and bisexual youth, MESMAC, Yorkshire.

Murray, D., 2001, 'Out with Homophobia', Youth Studies Australia 20(1), viewed 29 August 2006, from http://0-web.ebscohost.com.raulib.rau.ac.za

Myburgh, C.P.H. \& Strauss, J., 2010, Research methodology study guide, University of Johannesburg, Johannesburg.

National Union of Teachers, 2004a, Tackling homophobic bullying. An issue for every teacher, viewed n.d., from http://www.teacher.org.uk

National Union of Teachers, 2004b, Supporting lesbian, gay, bisexual and transgender students. An issue for every teacher, viewed n.d., from http://www.teacher.org.uk
Neuman, W.L., 1997, Social research methods: Qualitative and quantitative approaches, Allyn \& Bacon, London.

Oliver, C. \& Candappa, M., 2003, Summary report: Tackling bullying: Listening to the views of children and young people, Institute of Education, Thomas Coram Research Unit, London.

Olweus, D., 2001, Bullying at school, Blackwell, Oxford.

Pervin, L.A. \& John, O.P., 2001, Personality: Theory and research, 8th edn., John Wiley \& Sons, New York.

Plummer, D., 2001, 'The quest for modern manhood: Masculine stereotypes, peer culture and the social significance of homophobia', Journal of Adolescence 24,1523.

Randall, P., 1996, A community approach to bullying, Trentham Books, London

Richardson, E., 2006, 'What can we do for our gay learners?', The Teacher 11(7),18.

Rudestam, K.E. \& Newton, R.R., 2001, Surviving your dissertation: A comprehensive guide to content and process, 2nd edn., Sage, London.

Sanders, C.E. \& Phye, G.D., 2004, Bullying. Implications for the classroom: A volume in the educational psychology series, Elsevier Academic Press, London.

Shaffer, D.R., 2002, Developmental psychology: Childhood \& adolescence, 6th edn. Wadsworth Thomson Learning, London.

Smithers, R., 2006, Homophobic bullying on the rise in schools, says charity, viewed 18 September 2006, from http://www.guardian.co.uk/gayrights/ story $/ 0,1859883.00 . h t m$

Sullivan, K., 2001, The anti-bullying handbook, Oxford University Press, Oxford.

Sullivan, K., Cleary, M. \& Sullivan, G., 2004, Bullying in secondary schools: What it looks like and how to manage it, Paul Chapman Publishing, London.

Tattum, D.P. \& Lane, D.A., 1994, Bullying in schools, Trentham Books Limited, Staffordshire.

The Bill of Rights, South African Constitution, Chapter 2, viewed 28 August 2006, from http://www.polity.org.za/html/govdocs/constitution/saconst02.html?rebookmark=1

Van Wyk, A., 2006, 'Already a fact - the only question is the form of it - gay-marriages', SA Business Beeld, 21 September, 40.

Weiten, W., 2007, Psychology: Themes \& variations, International Student edn., Thomson \& Wadsworth, Las Vegas.

Westen, D., 1999, Psychology. Mind, brain \& culture, 2nd edn., Wiley \& Sons, New York.

Wicks-Nelson, R. \& Israel, A.C., 2003, Behavior disorders of childhood, 5th edn., Prentice Hall, New Jersey. 